\title{
ISOLATED IDENTIFIED APLYSIA NEURONS IN CELL CULTURE ${ }^{1}$
}

\author{
DANIEL DAGAN ${ }^{2}$ AND IRWIN B. LEVITAN ${ }^{3}$
}

Friedrich Miescher-Institut, Basel, Switzerland

\begin{abstract}
Methods have been developed for primary culture of large identified Aplysia neurons. Aplysia ganglia were treated with neutral protease to soften the connective tissue sheath. Individual neurons were isolated either by manipulation with tungsten needles or by tying off their axons with fine nylon filament and were immobilized in a chick plasma clot or a solution of methylcellulose. Somata up to approximately $300 \mu \mathrm{m}$ in diameter extended long processes within several hours in culture. A single neuron produced as many as 10 processes which could grow at different rates. Intracellular recordings showed spontaneous and evoked action potentials in neurons cultured for up to 6 weeks. Electrical synapses formed between pairs of neurons in culture. In several culture dishes containing neurons from buccal ganglia, electrical coupling was observed between $90 \%$ of the cell pairs tested. This primary culture system currently is being used to compare the electrical and biochemical properties of neuronal processes with those of cell bodies and to study the conditions necessary for process regeneration and synapse formation between isolated identified neurons.
\end{abstract}

The central ganglia of invertebrates are widely used for pharmacological, biochemical, and electrophysiological studies of neuronal function. These ganglia often contain extraordinarily large neurons, some of which can be identified reliably from one animal to the next on the basis of morphological, electrical, and chemical criteria (Frazier et al., 1967; Gainer, 1972; Muller, 1979). The cell bodies of these neurons are arranged around the periphery of the ganglion and are readily accessible for experimental analysis. In contrast, the neuronal processes (Winlow and Kandel, 1976) penetrate into a complex and relatively inaccessible neuropil in which all synaptic contacts occur (Frazier et al., 1967).

In order to gain access to the processes of invertebrate neurons, some investigators have turned to cell culture techniques (Chen et al., 1971; Kaczmarek et al., 1979; Ready and Nicholls, 1979). In early experiments, Chen et al. (1971) were able to obtain viable isolated identified Aplysia neurons, but no neurite regeneration was observed. More recently, Kaczmarek et al. (1979), using 60$\mu \mathrm{m}$ diameter neurosecretory bag cells from Aplysia, and Ready and Nicholls (1979), using identified neurons (up to $100 \mu \mathrm{m}$ in diameter) from the leech, have observed

\footnotetext{
'We are grateful to Drs. D. Ready and J. Nicholls for kindly providing us with nylon filament, to Mr. H. D. Kusmierz for help with the time-lapse cinematography, and to Mrs. M. Villermain for excellent technical assistance. D. Dagan was supported by a long term fellowship from the European Molecular Biology Organization.

"Permanent address: Faculty of Medicine, Technion, Haifa, Israel.

To whom reprint requests should be addressed at Friedrich Miescher-Institut, P. O. Box 273, CH-4002 Basel, Switzerland.
}

regeneration of processes in primary cultures. We have developed techniques to obtain the formation of long neurites from cultured Aplysia neurons as large as 300 $\mu \mathrm{m}$ in diameter; this has not been possible using previous methodology. One of the major modifications introduced is the immobilization of the large neurons, either in a plasma clot or under a layer of viscous methylcellulose solution. In this communication, we present the details of the primary culture technique and a preliminary description of some properties of the cultured neurons and their regenerating processes. Some of these findings have been published previously in abstract form (Dagan and Levitan, 1980).

\section{Materials and Methods}

Animals. Aplysia californica weighing 200 to $300 \mathrm{gm}$ were obtained from Pacific Bio-Marine Laboratories, Venice, CA, or from Marine Specimens Unlimited, $\mathrm{Pa}$ cific Palisades, CA. Young animals weighing 15 to $40 \mathrm{gm}$ were obtained from Marine Specimens Unlimited between January and May. Animals were maintained in Instant Ocean (Aquarium Systems, Inc., Eastlake, $\mathrm{OH}$ ) artificial sea water at 18 to $21^{\circ} \mathrm{C}$. Lights in the animal room were on from 8:00 A.M. to 8:00 P.M.

Solutions. A stock salt solution consisting of $780 \mathrm{~mm}$ $\mathrm{NaCl}, 14.2 \mathrm{~mm} \mathrm{KCl}, 108 \mathrm{~mm} \mathrm{MgCl}_{2}$, and $21 \mathrm{~mm} \mathrm{CaCl}_{2}$ was mixed with an equal volume of Leibovitz-15 tissue culture medium (Gibco). The concentration of salts in the resulting solution (solution A) is the same as that in normal Aplysia medium (Levitan and Barondes, 1974). Solution A was sterilized by filtration through a $0.2-\mu \mathrm{m}$ Nalgene filter and was used to rinse ganglia prior to 
desheathing and cell isolation and to prepare other solutions as described below.

Tissue culture medium containing methylcellulose (Iscove and Schreier, 1978) was prepared by stirring $5 \mathrm{gm}$ of methylcellulose (Methocel MC, premium 4000 centipoise, Dow-Corning) in $400 \mathrm{ml}$ of solution $\mathrm{A}$ at $4^{\circ} \mathrm{C}$ for 3 to $4 \mathrm{hr}$. This viscous solution was supplemented with 80 $\mathrm{ml}$ of solution A containing $10 \mathrm{gm}$ of $\mathrm{D}$-glucose. Prior to use, the medium was supplemented with fetal calf serum to a final concentration of $4 \%$ and either gentamicin (Sigma; $10 \mathrm{mg} / 100 \mathrm{ml}$ ) or streptomycin/penicillin (Gibco; 1000 units each $/ 100 \mathrm{ml}$ ) to give solution $\mathrm{B}$. The final concentration of methylcellulose was $1 \%$. For some experiments, an Aplysia salt solution supplemented with amino acids and vitamins (Levitan and Barondes, 1974), buffered with HEPES (4-(2-hydroxyethyl)-1-piperazineethanesulfonic acid, $\mathrm{pH}$ 7.4), and containing methylcellulose, glucose, serum, and antibiotics as described above was used with similar results.

Cell isolation. Ganglia were incubated in a $1 \%(\mathrm{w} / \mathrm{v})$ solution of neutral protease (Boehringer Mannheim; see Kaczmarek et al., 1979) in solution A for $15 \mathrm{hr}$ at $15^{\circ} \mathrm{C}$ with gentle shaking. After incubation, ganglia were rinsed with solution $A$ and pinned through the sheath to Sylgard dishes in solution A or B (see below). Sylgard dishes, insect pins, and all dissecting tools were autoclaved prior to use. The sheath was removed with the aid of a scalpel and microscissors. Cells were identified tentatively on the basis of size, location, and pigmentation (Frazier et al., 1967; Gardner, 1971; Kandel, 1976); they were isolated either by manipulation with an electrolytically etched tungsten needle (Teledyne, Inc.) or by tying a loop of fine nylon filament (a gift from Drs. D. Ready and J. Nicholls) around the axon close to the cell body (Ready and Nicholls, 1979). The filament was found to be most useful for isolation of large $(>200 \mu \mathrm{m})$ identified neurons; dissociation with the tungsten needle was used for smaller cells. Both methods provided isolated neuronal somata free of processes.

Cell culture. Individual cells or groups of cells isolated in solution A were transferred to a 5 - $\mu$ l drop of chick plasma (Gibco; lyophilized and redissolved in solution $\mathrm{A}$ ) in a 35-mm plastic Petri dish (Corning). The plasma then was clotted with $10 \mu \mathrm{l}$ of thrombin (Topostasin, Hoffmann-La Roche, $600 \mathrm{NIH}$ units/ml of solution A), and the clot was maintained in $2 \mathrm{ml}$ of solution A supplemented with $2 \mathrm{gm} / 100 \mathrm{ml}$ of glucose, $4 \%$ fetal calf serum, and $10 \mathrm{mg} / 100 \mathrm{ml}$ of gentamicin. The alternative method was to dissociate cells in the viscous solution B directly on 13-mm diameter glass coverslips (Corning) placed in 35-mm Petri dishes and to maintain the cells on the coverslips in $2 \mathrm{ml}$ of solution B. All culture dishes were kept at 20 to $22^{\circ} \mathrm{C}$ in the dark. Up to six dishes were placed in a $115-\mathrm{mm}$ diameter Petri dish together with a small container of sterile water to maintain high humidity. Half of the medium was replaced every 3 to 4 days. Dissection and plating of cells, as well as changing of medium, were carried out in a sterile laminar flow hood.

Microscopy. Cells were photographed with phase optics using a Zeiss inverted microscope. Time-lapse cinematography was carried out with an Ariflex 16-mm film camera mounted on a Leitz inverted microscope. Se- quences were filmed at a rate of one frame per min, and films were analyzed by tracing identified processes from consecutive frames projected onto millimeter paper.

Electrical recording. Conventional techniques were used for intracellular recording and for passing current.

\section{Results}

Neurite growth. Isolated neuronal cell bodies ranging in diameter from $50 \mu \mathrm{m}$ to over $700 \mu \mathrm{m}$ remained viable in cell culture for up to 6 weeks. Somata up to about 300 $\mu \mathrm{m}$ in diameter extended large growth cones with fine filopodia, often as soon as $2 \mathrm{hr}$ after isolation, either in three dimensions in the plasma clot (Fig. $1 A$, arrows) or in two dimensions along the surface of the coverslip under methylcellulose (Fig. 1, $B$ and $F$ to $I$ ). The neuron R15 shown in Figure $1 B$ was taken from a 15 -gm animal and was approximately $285 \mu \mathrm{m}$ in diameter. This was the only R15 which extended neurites under our culture conditions. Although cells occasionally extended only a single process, most were clearly multipolar (Fig. $1 H$ ), and extensive branching occurred (Fig. $1, G$ and $I$ ). Processes often extended for distances many times the diameter of the cell body, and extensive networks of fibers formed when several cells were placed on a coverslip (Fig. 1I). Cells taken from the abdominal, cerebral, pleural, and buccal ganglia of Aplysia all extended processes; neurite outgrowth was most rapid and extensive with cells from the buccal ganglia. Cell bodies greater than approximately $300 \mu \mathrm{m}$ in diameter (Fig. 1, $C$ to $E$; many of the identified neurons in Aplysia fall into this size category) only rarely extended neurites in culture. On the other hand, many such cells remained viable as determined by intracellular electrical recording (see Fig. 2).

Time-lapse cinematography revealed that, although somata were held rigidly in place in the plasma clot, the methylcellulose medium did not prevent rotation and other movement of the cell body. Under the latter conditions, only the neurites were attached to the substrate. Rates of linear extension of neurites (measured by timelapse cinematography) ranged from 4 to $40 \mu \mathrm{m} / \mathrm{hr}$ at $20^{\circ} \mathrm{C}$. The most rapid and extensive growth was observed with neurons taken from small animals (15 to $40 \mathrm{gm}$ ). The higher growth rates are similar to those reported for mammalian neurons at $37^{\circ} \mathrm{C}$ (Hughes, 1953). When several neurons were filmed in the same field, it was observed that palpation of the process of one cell by the growth cone of another resulted in either continued extension of the two processes together or in retraction of the process bearing the palpating growth cone. Rates of linear retraction exceeded those of extension and reached as high as $70 \mu \mathrm{m} / \mathrm{hr}$.

Electrical recording. Many cells exhibited spontaneous electrical activity for at least several weeks in culture (Fig. 2). Other cells did not fire spontaneously but had resting potentials of -30 to $-50 \mathrm{mV}$ and produced action potentials in response to injection of depolarizing current (Fig. 3). The pattern of spontaneous activity exhibited by a metacerebral neuron (pictured in Fig. $1 E$ ) after 9 days in culture is shown in Figure $2 A$. Although metacerebral cells fire only rarely in situ, this cultured neuron fired action potentials very regularly 

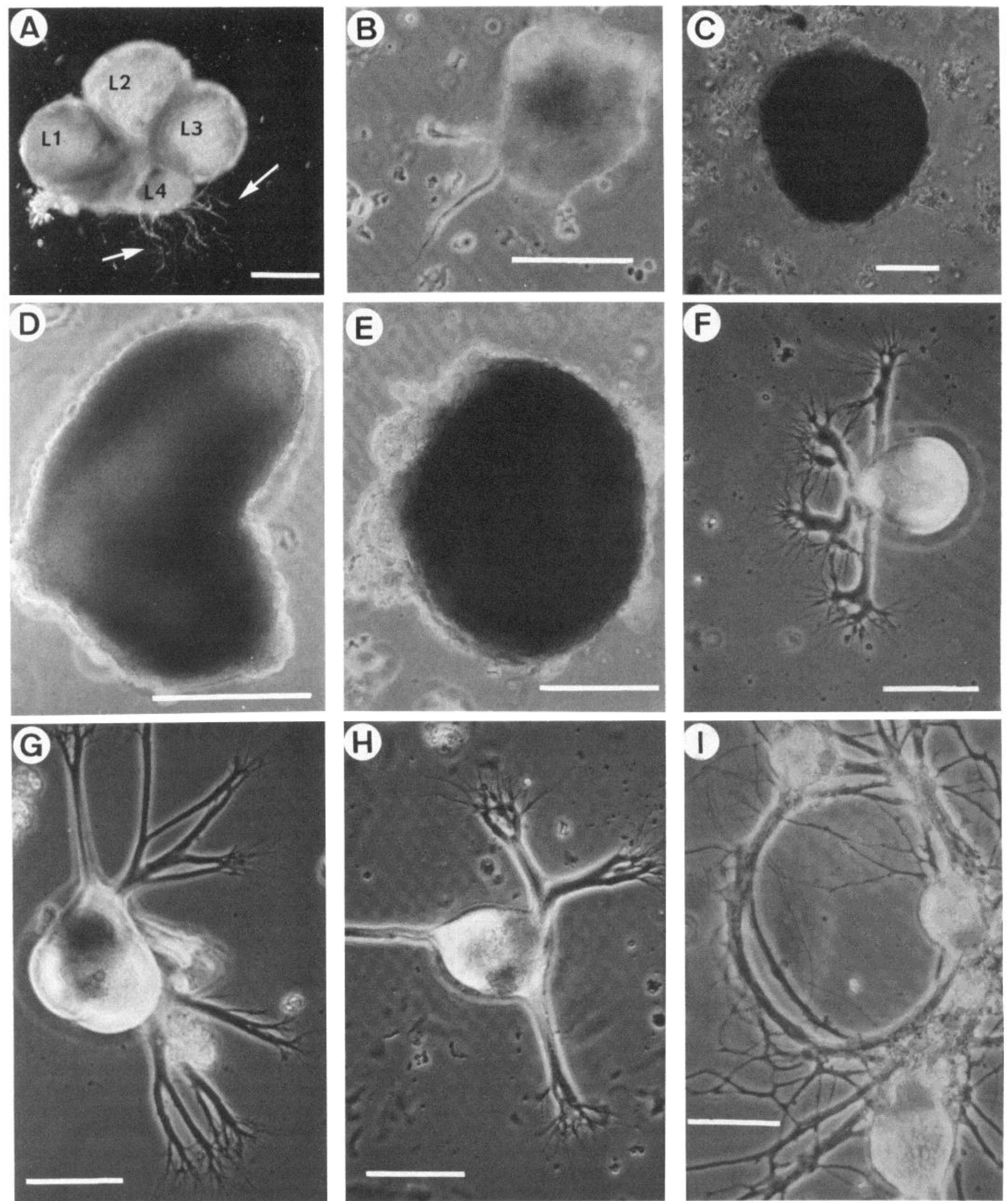

Figure 1. Phase contrast micrographs of cultured Aplysia neurons. A, A cluster of four cells (L1, L2, L3, and L4) from the left rostral quadrant of the abdominal ganglion photographed after 3 days of culture in a plasma clot. A series of fine neurites can be seen emerging from the lower right (arrows). $B$ to $I$, Neurons cultured under methylcellulose. Identified neurons, R15 (B, 1 day in culture), R2 ( $C, 7$ days in culture), L11 $(D, 7$ days in culture), and a metacerebral neuron $(E, 9$ days in culture) were alive at the time these pictures were taken as determined by intracellular recording (see Fig. 3, for example). Note the fine filopodia at the ends of the growth cones in unidentified buccal neurons after 3 days in culture $(F$ to $H)$. $I$, Three buccal neurons after 6 days in culture. An extensive network of neuronal processes has formed. These three cells were electrically coupled as determined by intracellular recording (see text). Bars: $A$ to $D, 200 \mu \mathrm{m} ; E, 125 \mu \mathrm{m} ; F$ to $I, 50 \mu \mathrm{m}$. 
during the entire 90-min recording period. Another metacerebral neuron also exhibited spontaneous regular firing after 2 days in culture (not shown). Figure $2 B$ shows the higher frequency firing exhibited by an unidentified neuron from the abdominal ganglion after 6 days in culture. This pattern was the same when the cell was re-impaled with a microelectrode 27 and $50 \mathrm{hr}$ later. The irregular beating activity observed in an identified R15 neuron from the abdominal ganglion (pictured in Fig. $1 B$ ) is illustrated in Figure $2 C$. Of the eight R15s from which we have recorded in culture, all exhibited spontaneous activity, but none showed the highly characteristic regular bursting pattern normally observed in situ (Strumwasser, 1967).

To investigate the formation of functional connections between isolated cells, recordings were made from pairs of cultured buccal neurons. Electrical coupling between buccal neurons has been reported in situ (Gardner, 1977), and we have found extensive coupling between dissociated cells in five separate buccal cultures. In several culture dishes, there were electrical synapses between as many as $90 \%$ of the cell pairs tested. Recordings from one such pair are shown in Figure 3. Hyperpolarizing current injected into one of the cells led to a 5 -mV hyperpolarization in the second cell (Fig. $3 A$ ), and action potentials evoked by depolarizing the first cell were seen as attenuated signals in the second cell (Fig. $3 A$ ). Furthermore, when sufficient depolarizing current was injected into the second cell, the current transferred to the first cell caused it to fire (Fig. $3 B$ ). It is worthy of note that cells imme-

A
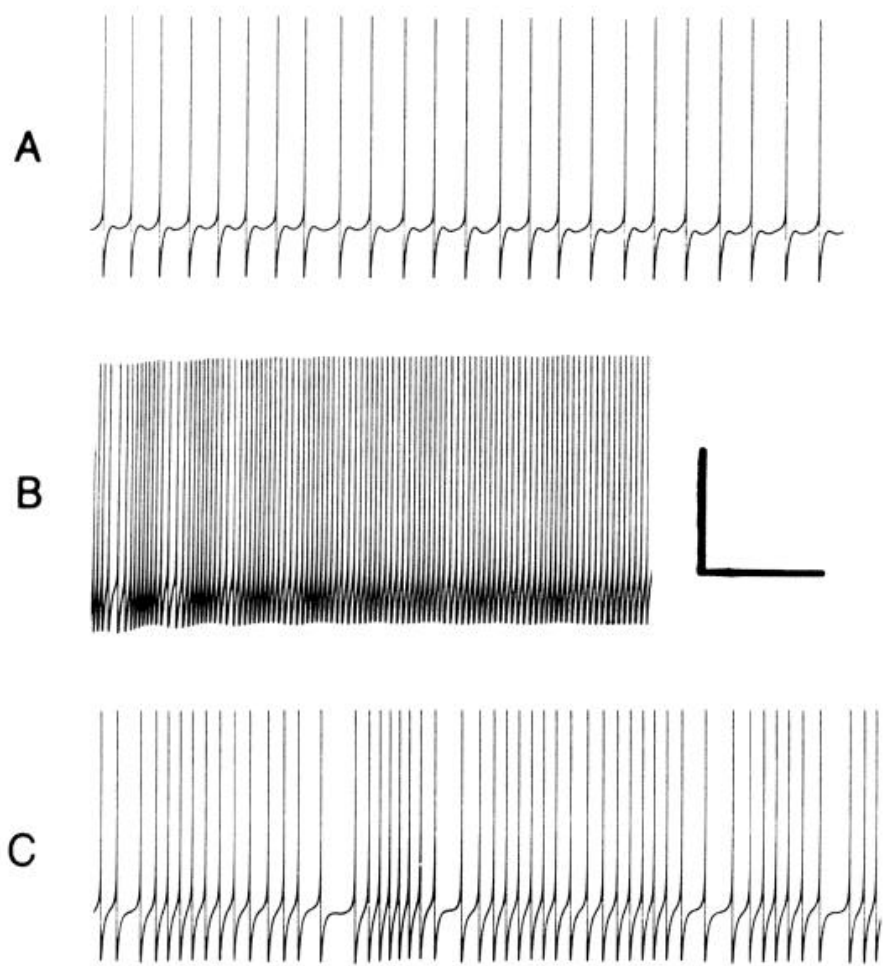

Figure 2. Spontaneous electrical activity in Aplysia neurons cultured under methylcellulose. $A$, A metacerebral neuron (pictured in Fig. $1 E$ ) after 9 days in culture. $B$, An unidentified abdominal ganglion neuron approximately $150 \mu \mathrm{m}$ in diameter after 6 days in culture. $C$, Neuron R15 (pictured in Fig. $1 B$ ) after 1 day in culture. Time calibration, $20 \mathrm{sec}$; voltage calibration, $40 \mathrm{mV}$.
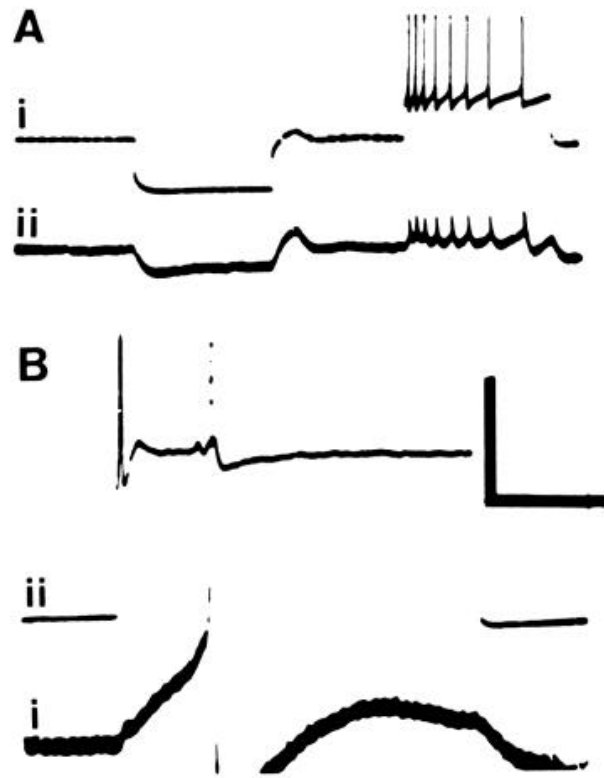

Figure 3. Electrical coupling between a pair of buccal neurons cultured for 5 days under methylcellulose. $A$, Injection of hyperpolarizing current $(0.5 \mathrm{nA})$ into cell $i$ (top trace) causes cell ii (bottom trace) to hyperpolarize as well. Injection of depolarizing current $(0.5 \mathrm{nA})$ into cell $i$ causes it to fire action potentials, which are seen as attenuated signals in cell ii. B. Injection of depolarizing current $(0.5 \mathrm{nA})$ into cell ii (top trace) causes it to fire a single action potential. The sustained depolarization allows sufficient current to spread to cell $i$ (bottom trace) for it to fire an action potential, which is seen as an attenuated signal in cell ii. Time calibration: $A, 1 \mathrm{sec} ; B, 200 \mathrm{msec}$. Voltage calibration: $A$, top trace, $100 \mathrm{mV}$; bottom trace, $20 \mathrm{mV}$. B, top trace, $40 \mathrm{mV}$; bottom trace, $10 \mathrm{mV}$.

diately adjacent to one another in a cluster often were not connected electrically, whereas electrical synapses could form between cells whose somata were far apart (for example, the three cells in Fig. $1 I$ were coupled electrically).

\section{Discussion}

There are numerous advantages in having primary cultures of large individual nerve cells. Many questions relating to properties of neuronal processes, growth cones, neurite extension, and synaptogenesis between identified neurons may be amenable to experimental attack for the first time in such a system. Previous investigators have described process formation and electrical coupling in cultures of invertebrate neurons up to approximately $100 \mu \mathrm{m}$ in diameter (Ready and Nicholls, 1979; Kaczmarek et al., 1979). However, neurite extension by larger cells has not been reported, probably because they adhere only very poorly to the substrate. None of our attempts to obtain attachment of large Aplysia neuronal cell bodies to various substrates met with success. Among the many substrates tested were glass, plastic, polylysine, collagen, fibronectin, and glutaraldehydefixed or non-fixed Aplysia aorta. We have circumvented this problem using two approaches, both involving immobilization of the soma, either in a plasma clot or under a viscous solution of methylcellulose. Under both conditions, neurons as large as $300 \mu \mathrm{m}$ in diameter rapidly extend neurites and form electrical synapses with other 
cells. Although we have not yet investigated the specificity of electrical coupling in detail, our finding of extensive coupling between buccal neurons in culture may be related to the fact that many buccal cells are coupled in situ (Gardner, 1977). Furthermore, as indicated under "Results," close proximity of neurons in the culture dish is not in itself sufficient to produce electrical synapses, suggesting that there may be some specificity in their formation. Whether chemical synapses also form in these cultures is not clear yet. A preliminary fine structure study (not shown) has revealed occasional profiles resembling the indented synapses previously described in Aply. sia abdominal ganglion (Bailey et al., 1979); however, in the absence of corroborative electrophysiological evidence, identification of these profiles as synaptic structures must remain tentative.

A primary issue is the extent to which these neurons retain their in situ properties in culture. Certainly, there are differences, perhaps the most striking of which is that these normally monopolar cells (Winlow and Kandel, 1976) almost invariably extend several neurites in culture (Fig. 1). A similar finding has been reported by Ready and Nicholls (1979) for leech neurons. In addition, the pattern of spontaneous activity in several cultured neurons (Fig. 2) is different from that in situ (Frazier et al., 1967; Strumwasser, 1967). It will be of interest to examine other morphological, electrical, and chemical properties of these cultured cells. It should be possible to record intracellularly from the large neurites and growth cones and to extend to identified neuronal processes the combined electrophysiological, biochemical, and pharmacological investigations (Levitan et al., 1979; Drummond et al., 1980) which have been restricted previously to cell bodies (Levitan, 1978).

\section{References}

Bailey, C., E. Thompson, V. Castellucci, and E. Kandel (1979) Ultrastructure of the synapses of sensory neurons that mediate the gill-withdrawal reflex in Aplysia. J. Neurocytol. 8: 415-444.

Chen, C., R. Von Baumgarten, and K. 'Takeda (1971) Pacemaker properties of completely isolated neurons in Aplysia. Nature New Biol. 233: 27-29.

Dagan, D., and I. Levitan (1980) Identified isolated Aplysia neurons cultured in vitro. Soc. Neurosci. Abstr. 6: 576.
Drummond, A., J. Benson, and I. Levitan (1980) Serotonininduced hyperpolarization of an identified Aplysia neuron is mediated by cyclic AMP. Proc. Natl. Acad. Sci. U. S. A. 77: 5013-5017.

Frazier, W., E. Kandel, I. Kupfermann, R. Waziri, and R. Coggeshall (1967) Morphological and functional properties of identified neurons in the abdominal ganglion of Aplysia. J. Neurophysiol. 30: 1288-1351.

Gainer, H. (1972) Patterns of protein synthesis in individual, identified molluscan neurons. Brain Res. 39: 369-385.

Gardner, D. (1971) Bilateral symmetry and interneuronal organization in the buccal ganglia of Aplysia. Science 173: 550553.

Gardner, D. (1977) Interconnections of identified multiaction interneurons in buccal ganglia of Aplysia. J. Neurophysiol. 40: $349-361$.

Hughes, A. F. (1953) Axonal elongation in regenerating nerve cells. J. Anat. 87: 150-162.

Iscove, N., and M. Schreier (1978) Clonal growth of cells in semisolid or viscous medium. In Immunological Methods, I. Lefkovits and B. Pernis, eds., pp. 379-385, Academic Press, New York

Kaczmarek, L., M. Finbow, J. Revel, and F. Strumwasser (1979) The morphology and coupling of Aplysia bag cells within the abdominal ganglion and in cell culture. J. Neurobiol. 10:535550.

Kandel, E. (1976) Cellular Basis of Behavior, Freeman \& Co., San Francisco.

Levitan, I. (1978) Adenylate cyclase in isolated Helix and Aplysia neuronal cell bodies: Stimulation by serotonin and peptide-containing extract. Brain Res. 154: 404-408.

Levitan, I., and S. Barondes (1974) Octopamine- and serotoninstimulated phosphorylation of specific protein in the abdominal ganglion of Aplysia californica. Proc. Natl. Acad. Sci. U. S. A. 71: 1145-1148.

Levitan, I., A. Harmar, and W. Adams (1979) Synaptic and hormonal modulation of a neuronal oscillator: A search for molecular mechanisms. J. Exp. Biol. 81: 131-151.

Muller, K. (1979) Synapses between neurons in the central nervous system of the leech. Biol. Rev. 54: 99-134.

Ready, D., and J. Nicholls (1979) Identified neurones isolated from leech CNS make selective connections in culture. Nature 281: 67-69.

Strumwasser, F. (1967) Types of information stored in single neurons. In Invertebrate Nervous Systems, C. A. G. Wiersma, ed., pp. 291-319, University of Chicago Press, Chicago.

Winlow, W., and E. Kandel (1976) The morphology of identified neurons in the abdominal ganglion of Aplysia californica. Brain Res. 112: 221-249. 